\title{
ENHANCED CONDUCTIVITY OF PEROVSKITE LITHIUM-ION CONDUCTORS UNDER THE INFLUENCE OF NANO-CELLULOSE FIBRES
}

\author{
"XIAOJUAN LU*, **, FENG ZHANG*, **, JING LI*, ** \\ *Hebei Key Lab of Power Plant Flue Gas Multi-Pollutants Control, \\ Department of Environmental Science and Engineering, North China Electric Power University, \\ Baoding, 071003, PR China \\ **MOE Key Laboratory of Resources and Environmental Systems Optimization, \\ College of Environmental Science and Engineering, North China Electric Power University, \\ Beijing, 102206, PR China \\ "E-mail: xiaojuanlv@hotmail.com
}

Submitted September 18, 2020; accepted December 27, 2020

\begin{abstract}
Keywords: Lithium-ion conductor, Nano-cellulose, Conductivity, Particle size
A perovskite type lithium-ion conductor $\mathrm{Li}_{0.33} \mathrm{La}_{0.56} \mathrm{TiO}_{3}$ was prepared and the influence of the addition of nano-cellulose in different amounts was investigated in this paper. The powders for making the pellets were prepared via the sol-gel method. The calcined powders were pressed into green pellets, which were subsequently sintered at high temperatures to attain densified pellets. Upon doping, the particle sizes of the calcined powders prepared via the sol-gel method were reduced. The total conductivities and the grain-boundary conductivities of the sintered pellets were enhanced with the addition of the nano-cellulose, while the grain conductivities were not necessarily increased. The total conductivity peaked at the addition of $1.5 \mathrm{~g}$ of nano-cellulose. The enhancement in the total conductivity resulted from an increase in the grain-boundary conductivity, which was attributed to the fact that the boundaries between the grains became indistinct. The indistinct grain boundaries facilitate the migration of lithium ions across the boundaries, thereby increasing the grain-boundary conductivity.
\end{abstract}

\section{INTRODUCTION}

Lithium-ion batteries with a high energy density and high potential have been widely investigated in order to meet the ever-growing demands of home electronics, battery-powered electric vehicles, as well as in military and aerospace applications. The current electrolytes used in lithium-ion batteries are normally organic liquid electrolytes, which pose safety hazards since they are flammable. Solid state electrolytes offer the advantages of higher safety and better stability over those of organic liquid electrolytes. Nitrides [1, 2], oxides [3-5], phosphates [6-9], sulfides [10, 11] and hydrides [12] are currently being investigated as potential solid state electrolytes. Among these potential electrolytes, oxides exhibit a good overall performance, especially perovskite-type $\mathrm{Li}_{3 x} \mathrm{La}_{2 / 3-x} \mathrm{TiO}_{3}$ (LLTO). A typical perovskite structure consists of a $\mathrm{TiO}_{6}$ octahedra and La-site cages formed by 12 oxygen ions belonging to the 8 octahedra. The vacancies on the La sites allow the lithium ions to migrate from one dodecahedral Lasite cage to the next one through square planar bottlenecks between the La sites. The ionic conductivity of $\mathrm{Li}_{3 x} \mathrm{La}_{2 / 3-x} \mathrm{TiO}_{3}$ depends on the $\mathrm{Li}$ ion concentration and the highest grain conductivity $\left(10^{-3} \mathrm{~S} \cdot \mathrm{cm}^{-1}\right)$ at room temperature, which is comparable to that of organic liquid electrolytes, was found at $x=0.11$ [13]. However, the major drawback of this material, just like other polycrystalline lithium conductors, is its intrinsically low grain-boundary conductivity, which is normally two orders of magnitude lower than the grain conductivity. Thus, the total conductivity of perovskite $\mathrm{Li}_{3 x} \mathrm{La}_{2 / 3-x} \mathrm{TiO}_{3}$ is low, in the order of $10^{-5} \mathrm{~S} \cdot \mathrm{cm}^{-1}$. In recent years, intensive research has been carried out to improve the total conductivity of $\mathrm{Li}_{3 x} \mathrm{La}_{2 / 3-x} \mathrm{TiO}_{3}$. According to the published results $[14,15]$, the elimination of resistive grain boundaries and the densification of the microstructure were found to be beneficial to enhance the total conductivity of $\mathrm{Li}_{3 x} \mathrm{La}_{2 / 3-x} \mathrm{TiO}_{3}$. In addition, doping the La-site with $\mathrm{Nd}$ [16], Ag [17] or Al [18], incorporating insulating second phases like $\mathrm{SiO}_{2}$ [19], $\mathrm{Al}_{2} \mathrm{O}_{3}$ [20] and $\mathrm{Bi}_{2} \mathrm{O}_{3}$ [21], or mixing with other lithium conducting materials, such as $\mathrm{Li}_{7} \mathrm{La}_{3} \mathrm{Zr}_{2} \mathrm{O}_{12}$ [22], $\mathrm{Li}_{1+x} \mathrm{Al}_{x} \mathrm{Ti}_{2-x}\left(\mathrm{PO}_{4}\right)_{3}$ [23] and $\mathrm{Li}_{3} \mathrm{PO}_{4}$ [21] have also been adopted by many groups. Apart from these previously-mentioned studies, a total conductivity of $1.52 \times 10^{-4} \mathrm{~S} \cdot \mathrm{cm}^{-1}$ was reported for a nano-sized LLTO [24], which indicates that a reduction on sizes could be helpful. 
Nanostructured cubic $\mathrm{Li}_{7} \mathrm{La}_{3} \mathrm{Zr}_{2} \mathrm{O}_{12}$ was successfully prepared by templating onto various cellulosic fibres [25]. Reducing sizes via templating seems feasible. Therefore, with the aim to enhance the conductivity, $\mathrm{Li}_{3 x} \mathrm{La}_{2 / 3-x} \mathrm{TiO}_{3}$ was prepared via templating onto nanocellulose fibres by using the sol-gel method in this study. The subsequent thermal treatment was carried out in a microwave oven to crystallise and densify the LLTO pellets.

\section{EXPERIMENTAL}

Stoichiometric $\mathrm{La}_{2} \mathrm{O}_{3}$ (Aladdin, $99.9 \%$ ) and $\mathrm{Li}_{2} \mathrm{CO}_{3}$ (Huadong, $98 \%$ ) were first weighed and dissolved in acetic acid (Damao, $99.9 \%$ ). The mixture solution was continuously stirred at $70{ }^{\circ} \mathrm{C}$ until a white homogenous solution was formed. Then titanium (IV) isopropoxide (Macklin, $99.9 \%$ ) was added in a stoichiometric ratio. Subsequently, the solution turned from white in colour to being transparent. The transparent solution was continuously stirred at $100{ }^{\circ} \mathrm{C}$ until a thick solution was formed. Different amounts of nano-cellulose $(0,1,2.5$, $2,2.5,3 \mathrm{~g}$ ) were put in a watch-glass and the formerlyobtained LLTO gel $(10 \mathrm{ml})$ was added to allow sufficient saturation. Then the nano-cellulose saturated with LLTO was dried in air before being annealed in a microwave oven (INNOV-CS-03M1600, Hunan Innvo-Tech Co. Ltd.). The annealing programme was set at $600{ }^{\circ} \mathrm{C}$ for a duration of $1 \mathrm{~h}$ followed by $900{ }^{\circ} \mathrm{C}$ for a duration of $2 \mathrm{~h}$ and the heating rate was $5{ }^{\circ} \mathrm{C} \cdot \mathrm{min}^{-1}$. After sufficient grinding (the grinding time was kept at $30 \mathrm{~min}$ for all the powders), the annealed powder was pressed into a coinshaped pellet $15 \mathrm{~mm}$ in diameter under the pressure of $10 \mathrm{MPa}$ for $10 \mathrm{~min}$. The green pellets were then sintered at $1200^{\circ} \mathrm{C}$ for $4 \mathrm{~h}$ in the microwave oven.

The microstructures were examined using a field emission scanning electron microscope (JSM-7800F). The particle size distribution was characterised by the laser diffraction method (BT-9300H). All the sintered pellets were polished and painted with silver paste on both sides in order to perform the electrochemical impedance spectra (EIS) analysis. The EIS measurements were carried out using a Princeton Versasta3 station by applying a stimulus amplitude of $10 \mathrm{mV}$ over the frequency range of $0.1-1 \times 10^{6} \mathrm{~Hz}$.

The conductivities $\sigma$ were calculated as follows:

$$
\sigma=d /\left(R^{*} A\right)
$$

where $d$ is the thickness of the pellet, $R$ is the impedance and $A$ is the electrode area of the pellet. The grain impedance and grain boundary impedance were determined by the equivalent circuit from the Nyquist plots. Therefore, the grain conductivity and grain-boundary conductivity were calculated using Equation 1 accordingly.

\section{RESULTS AND DISCUSSION}

The particle size distributions of LLTO $+x$ g nanocellulose powders after calcination are shown in Figure 1 . The LLTO powders without nano-cellulose exhibited a tetra-modal distribution with distinct maxima centred at $4 \mu \mathrm{m}, 14 \mu \mathrm{m}, 31 \mu \mathrm{m}$ and $107 \mu \mathrm{m}$ and its D50 was close to $38.48 \mu \mathrm{m}$. When added to the $1 \mathrm{~g}$ nanocellulose, the powder of LLTO $+1 \mathrm{~g}$ exhibited a tri-modal distribution with distinct maxima centred at $4 \mu \mathrm{m}$, $21 \mu \mathrm{m}$ and $117 \mu \mathrm{m}$ and its D50 reduced to $21.44 \mu \mathrm{m}$. The reduced D50 indicated that the particle size of the LLTO was reduced under the influence of the nano-cellulose. The powder of LLTO $+1.5 \mathrm{~g}$ still presented a tri-modal distribution with distinct maxima centred at $4 \mu \mathrm{m}, 28 \mu \mathrm{m}$ and $117 \mu \mathrm{m}$ and its D50 was close to $26.90 \mu \mathrm{m}$. When added to the $2 \mathrm{~g}$ nano-cellulose, the powder of LLTO + $2 \mathrm{~g}$ evolved into a tetra-modal distribution with a D50 reduced to $26.26 \mu \mathrm{m}$. When the amount of nano-cellulose increased to 2.5 and $3 \mathrm{~g}$, the D50 of the powders was reduced greatly to 13.67 and $10.07 \mu \mathrm{m}$, respectively. In general, the particle size was reduced by the addition of nano-cellulose. The specific surface area for LLTO, LLTO $+1 \mathrm{~g}$, LLTO $+1.5 \mathrm{~g}$, LLTO $+2 \mathrm{~g}$, LLTO $+2.5 \mathrm{~g}$ and LLTO $+3 \mathrm{~g}$ nano-cellulose was determined as $22.12 \mathrm{~m}^{2} \cdot \mathrm{g}^{-1}, 29.03 \mathrm{~cm}^{2} \cdot \mathrm{g}^{-1}, 24.57 \mathrm{~cm}^{2} \cdot \mathrm{g}^{-1}, 27.83 \mathrm{~cm}^{2} \cdot \mathrm{g}^{-1}$, $31.85 \mathrm{~cm}^{2} \cdot \mathrm{g}^{-1}$ and $39.72 \mathrm{~cm}^{2} \cdot \mathrm{g}^{-1}$, respectively. The specific area basically decreased as the amount of nano-cellulose increased.

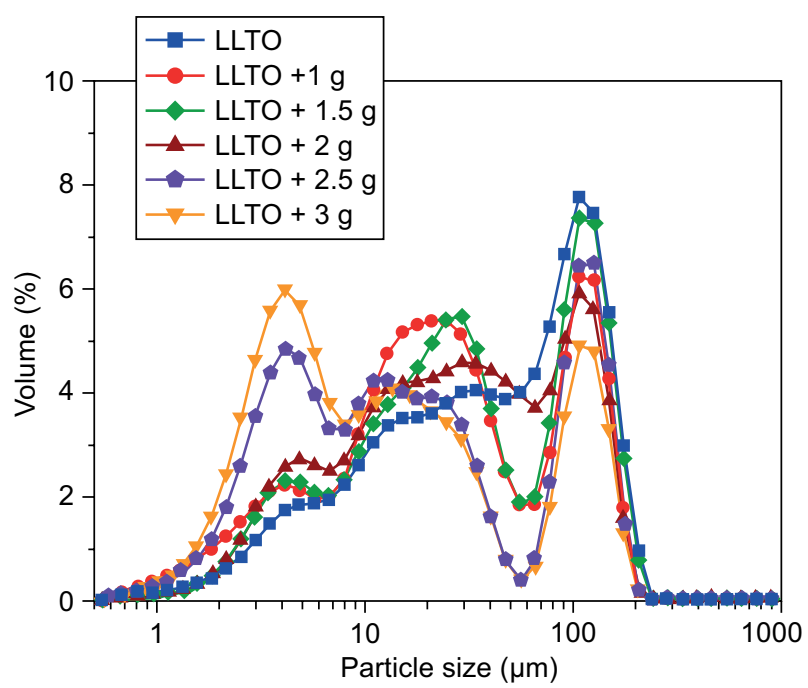

Figure 1. Particle size distribution of the LLTO $+x$ g nanocellulose.

The SEM photos of the LLTO and LLTO $+x \mathrm{~g}$ nano-cellulose powders after calcination are shown in Figure 2. The particles of the LLTO powders without the nano-cellulose had a spherical shape. Upon adding $1 \mathrm{~g}$ of nano-cellulose, the shape of the particles started to become elongated. When the addition of nano-cellulose 
reached $1.5 \mathrm{~g}$, the spherical shape in the LLTO evidently changed into a thin laminar shape. Moreover, the particle sizes became much smaller. As the amount of nanocellulose increased further, the particles changed into irregular multifaceted ones. Another feature about the particles after adding the nano-cellulose was that they tended to agglomerate more.

The electrochemical impedance spectra of the sintered LLTO and LLTO $+x \mathrm{~g}$ nano-cellulose pellets were measured at room temperature and the Nyquist plots are shown in Figure 3. The equivalent circuit is shown in the inset of Figure 3, comprising one resistor, one Warburg element in series with two pairs of a resistor and a CPE (constant phase element) in parallel.

The total conductivity, grain conductivity and grain-boundary conductivity were plotted against the amount of nano-cellulose, shown in Figure 4. Generally, the total conductivity increased under the influence of the nano-cellulose. Compared to the sample without the nano-cellulose, the grain-boundary conductivities

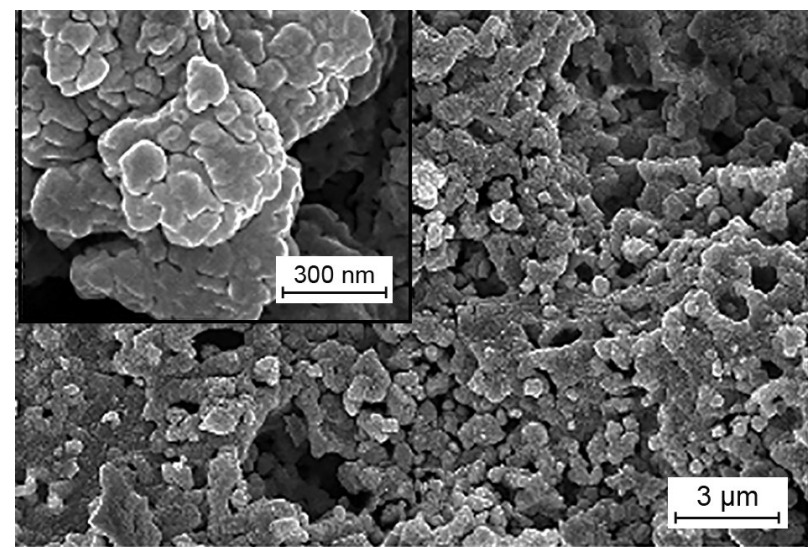

a) LLTO

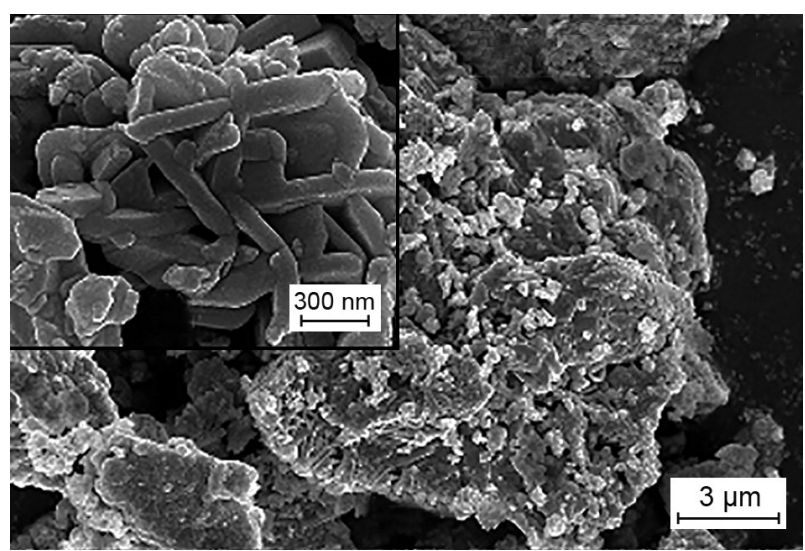

c) $\mathrm{LLTO}+1.5 \mathrm{~g}$

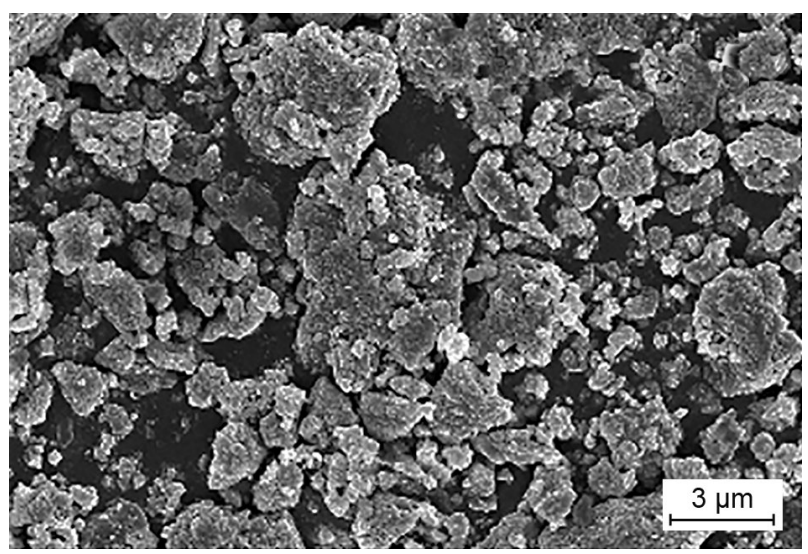

e) $\mathrm{LLTO}+2.5 \mathrm{~g}$

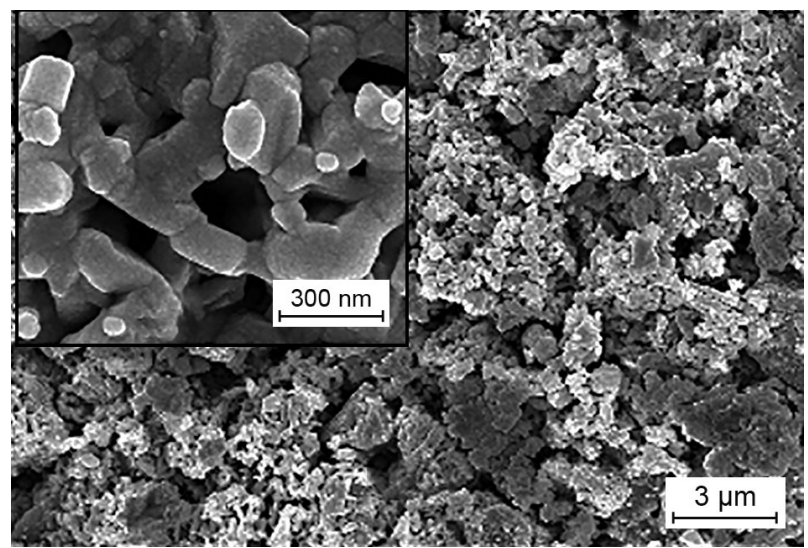

b) $\mathrm{LLTO}+1 \mathrm{~g}$

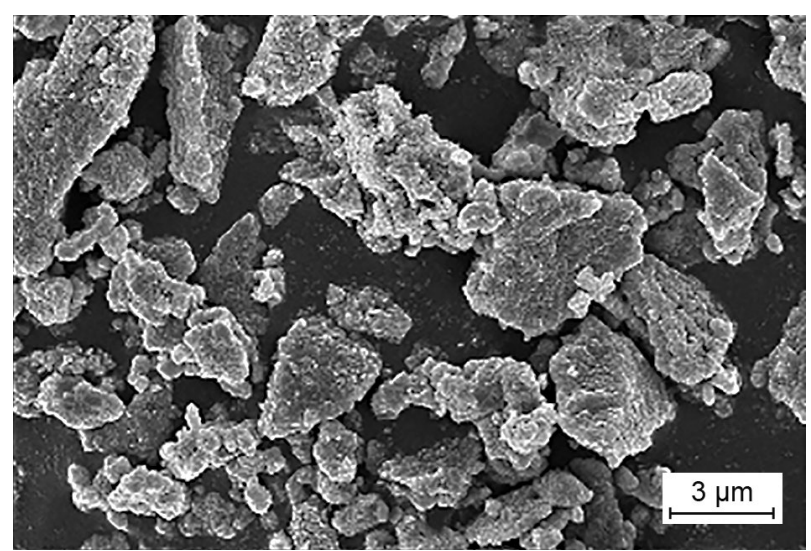

d) $\mathrm{LLTO}+2 \mathrm{~g}$

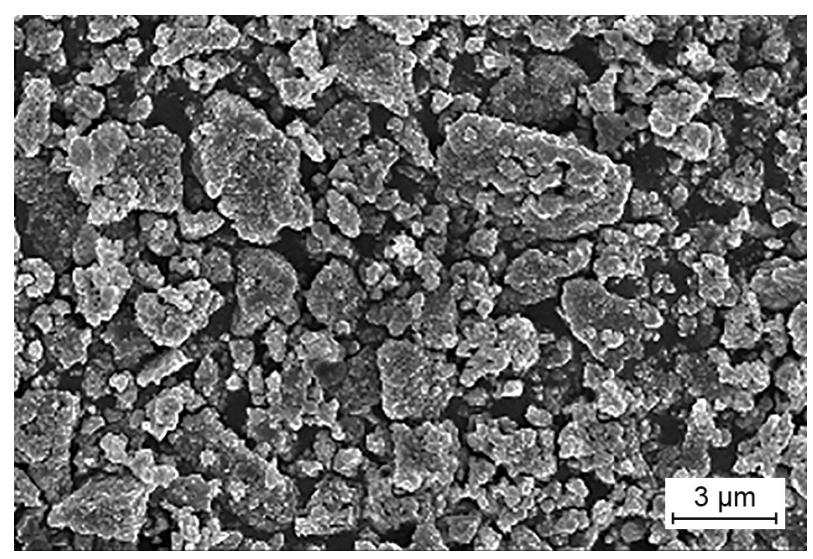

f) LLTO + $3 \mathrm{~g}$

Figure 2. SEM photos of the LLTO and LLTO $+x$ g nano-cellulose after calcination. 
of the samples with nano-cellulose were all increased to varying degrees. The total conductivity followed the same trend as the grain-boundary conductivity and both maximised at $1.5 \mathrm{~g}$ nano-cellulose. While the maximum grain conductivity resided at a slightly different doping amount, $2 \mathrm{~g}$. The SEM photos of the fractured surfaces of the LLTO and LLTO $+x \mathrm{~g}$ nano-cellulose pellets are shown in Figure 5. It was found that the boundaries between the grains were very clear in the LLTO without the nano-cellulose, while the boundaries became not so distinct and inseparable with the addition of the nanocellulose. It was thought that the enhanced conductivity of the LLTO with the nano-cellulose was attributed to the indistinct grain boundaries, which indicated that the nano-cellulose effect was mainly facilitating the migration of lithium ions across the grain boundary. The densities of the samples with the nano-cellulose were all higher than the density of the sample without the nano-

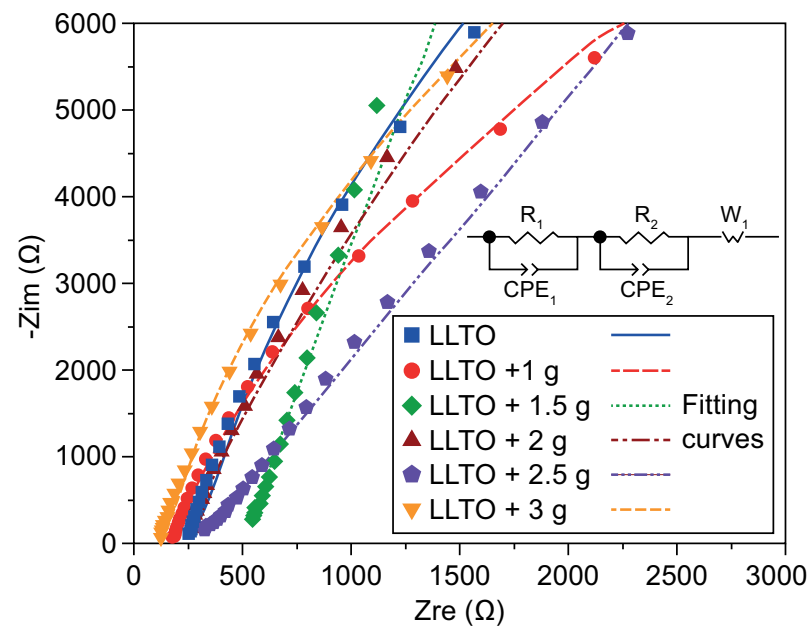

Figure 3. Nyquist plots and fitting curves of the LLTO and LLTO $+x$ g nano-cellulose.

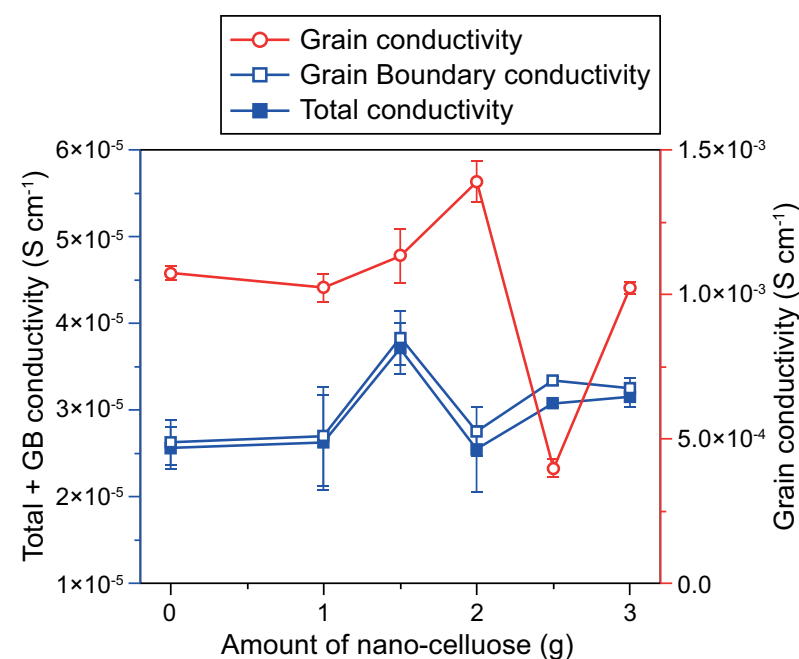

Figure 4. The conductivities of the samples against the nanocellulose amount. cellulose. The density of the samples with the nanocellulose did not show a clear trend with the amount of nano-cellulose. However, the densities of the samples corresponded well with the total conductivities.

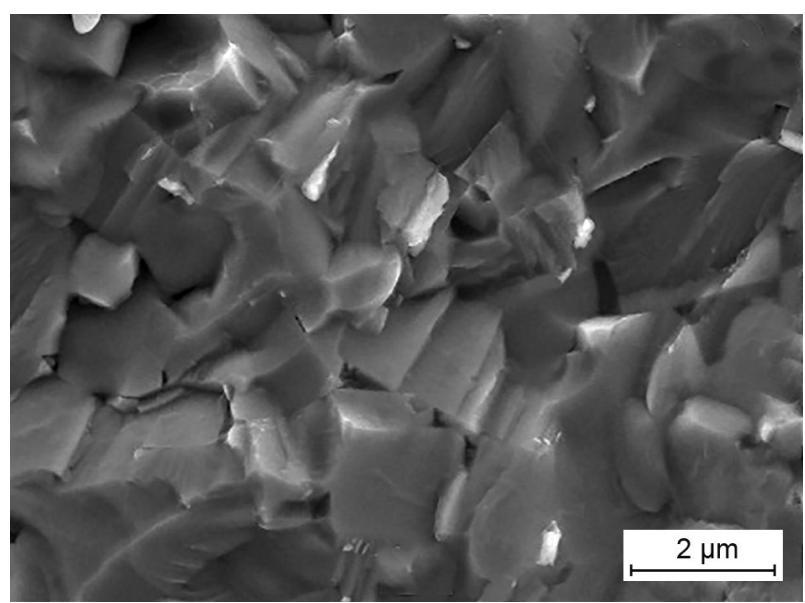

a) LLTO

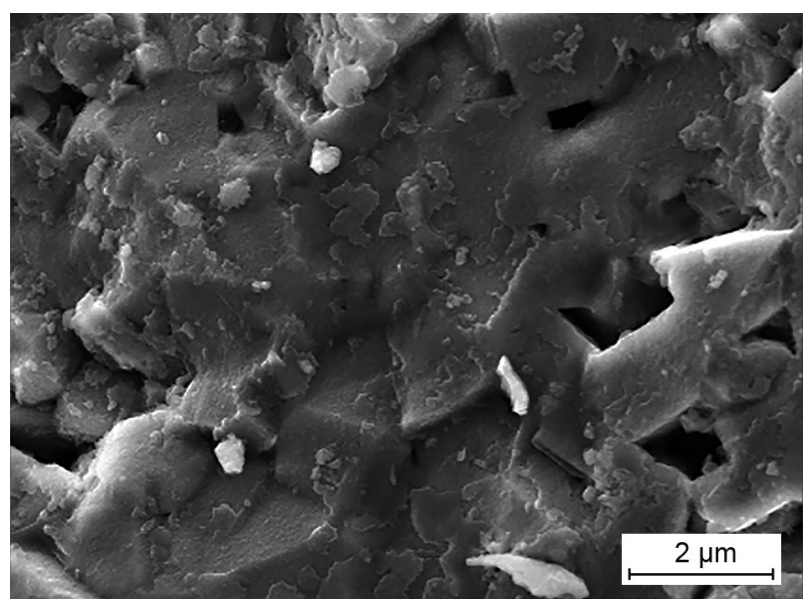

b) $\mathrm{LLTO}+1 \mathrm{~g}$

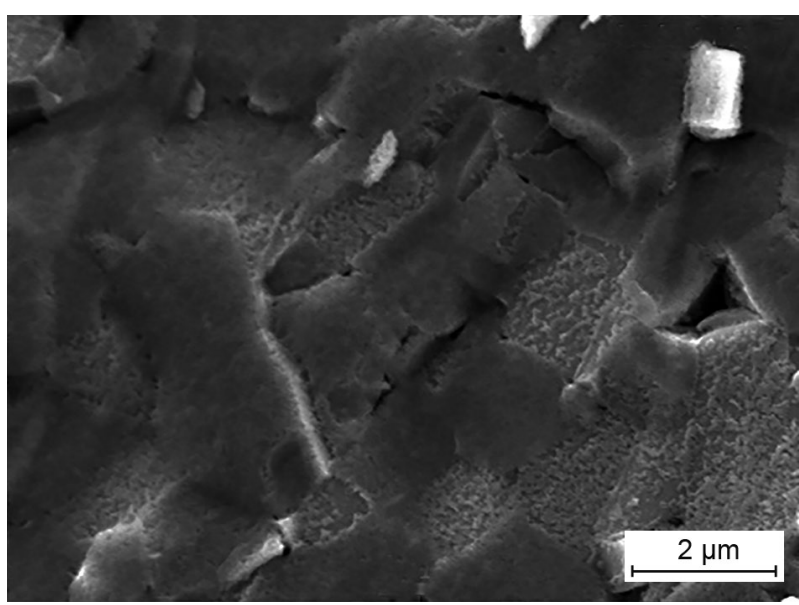

c) $\operatorname{LLTO}+1.5 \mathrm{~g}$

Figure 5. SEM photos of the LLTO and LLTO $+x$ g nanocellulose pellets. (Continue on next page) 


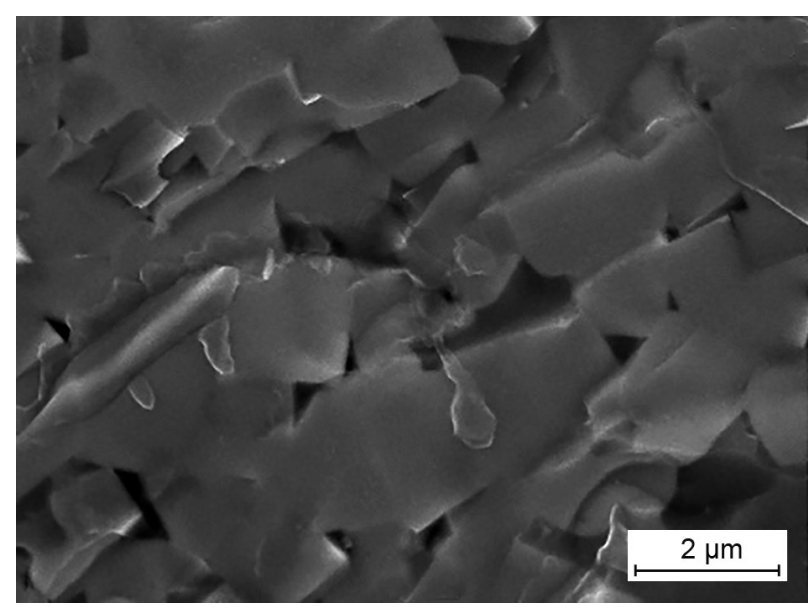

d) LLTO + 2 g

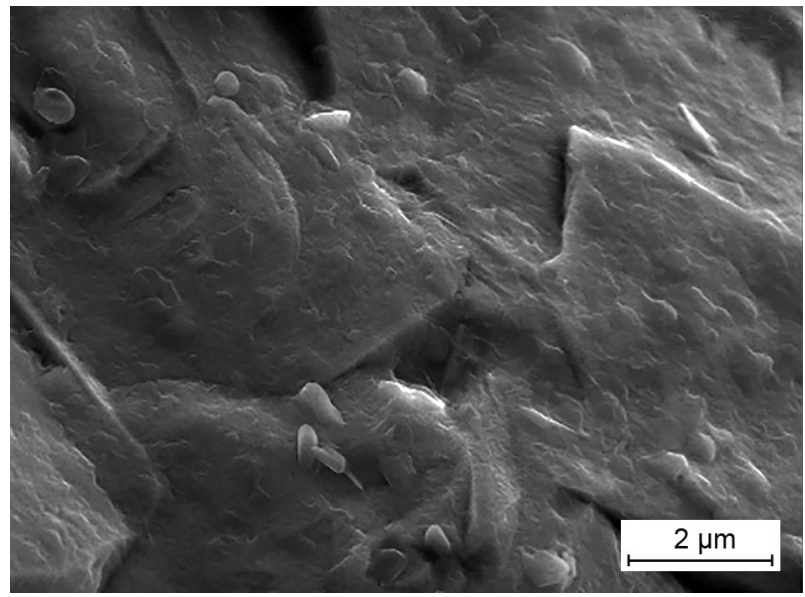

e) $\operatorname{LLTO}+2.5 \mathrm{~g}$

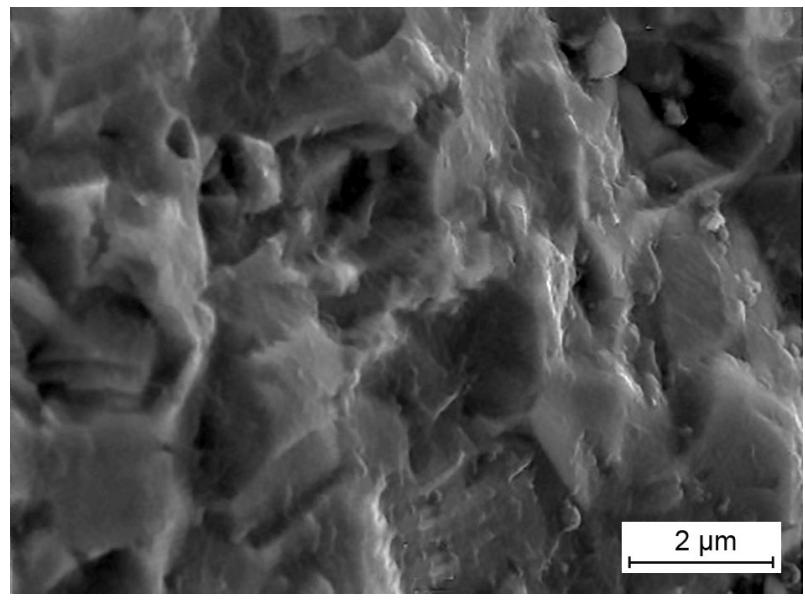

f) $\mathrm{LLTO}+3 \mathrm{~g}$

Figure 5. SEM photos of the LLTO and LLTO $+x$ g nanocellulose pellets.

\section{CONCLUSIONS}

A perovskite-type $\mathrm{Li}_{0.33} \mathrm{La}_{0.56} \mathrm{TiO}_{3}$ was tuned by nano-cellulose via the sol-gel method. The particle sizes were reduced after adding nano-cellulose and the total conductivity was enhanced under the influence of the nano-cellulose. The total conductivity of the doped samples peaked at $1.5 \mathrm{~g}$ of nano-cellulose. Upon the addition, the boundaries between the grains became indistinct, which was thought to contribute to the enhancement of the total conductivity.

\section{Acknowledgement}

This research has been financially supported by Natural Science Foundation of Hebei province (No. E2018502014) and the Scientific Research Foundation for Returned Overseas Chinese Scholars, State Education Ministry.

\section{REFERENCES}

1. Mani P.D., Saraf S., Singh V., Real-Robert M., Vijayakumar A., Duranceau S.J., Seal S., Coffey K.R. (2016): Ionic conductivity of bias sputtered lithium phosphorus oxy-nitride thin films. Solid State Ionics, 287, 48-59. doi: 10.1016/j.ssi. 2016.01.046

2. Nowak S., Berkemeier F., Schmitz G. (2015): Ultra-thin LiPON films - Fundamental properties, application in solid state thin film model batteries. Journal of Power Sources, 275, 144-150. doi: 10.1016/j.jpowsour.2014.10.202

3. Huang B., Zhong S., Luo J., Huang Z., Wang C.A. (2019): Highly dense perovskite electrolyte with a high $\mathrm{Li}^{+}$conductivity for Li-ion batteries. Journal of Power Sources, 429, 75-79. doi: 10.1016/j.jpowsour.2019.04.117

4. Rettenwander D., Redhammer G., Preishuber-Pflügl F., Cheng L., Miara L., Wagner R., Welzl A., Suard E., Doeff M.M., Wilkening M., Fleig J., Amthauer G. (2016): Structural and electrochemical consequences of $\mathrm{Al}$ and $\mathrm{Ga}$ cosubstitution in $\mathrm{Li}_{7} \mathrm{La}_{3} \mathrm{Zr}_{2} \mathrm{O}_{12}$ solid electrolytes. Chemistry of Materials, 28, 2384-2392. doi: 10.1021/acs.chemmater. $6 \mathrm{~b} 00579$

5. Cheng X., Wang J.L., Qiang W.J., Huang B.X. (2020): Improvement in electronic conductivity of perovskite electrolyte by variable-valence element doping. Journal of the American Ceramic Society, 103, 3698-3705. doi: 10.1111/ jace. 17080

6. Zhang P., Matsui M., Takeda Y., Yamamoto O., Imanishi N. (2014): Water-stable lithium ion conducting solid electrolyte of iron and aluminum doped NASICON-type $\mathrm{LiTi}_{2}\left(\mathrm{PO}_{4}\right)_{3}$. Solid State Ionics, 263, 27-32. doi: 10.1016/j. ssi.2014.04.017

7. Ma F., Zhao E., Zhu S., Yan W., Sun D., Jin Y., Nan C. (2016): Preparation and evaluation of high lithium ion conductivity $\mathrm{Li}_{13} \mathrm{Al}_{03} \mathrm{Ti}_{17}\left(\mathrm{PO}_{4}\right)_{3}$ solid electrolyte obtained using a new solution method. Solid State Ionics, 295, 7-12. doi: 10.1016/j.ssi.2016.07.010

8. Mahmoud M., Cui Y., Rohde M., Ziebert C., Link G., Seifert H. (2016): Microwave crystallization of lithium aluminum germanium phosphate solid-state electrolyte. Materials, 9, 506-520. doi: 10.3390/ma9070506

9. Lu X., Meng F., Huang S., Zhao D. (2018): Enhanced ionic conductivity and chemical stability of $\mathrm{Li}_{1.3} \mathrm{Al}_{0.3} \mathrm{Ti}_{1.7}\left(\mathrm{PO}_{4}\right)_{3}$ by doping of $\mathrm{WO}_{3}$, Materials Letters, 230,177-179. doi: 10.1016/j.matlet.2018.07.103 
10. Arnold W., Buchberger D.A., Li Y., Sunkara M., Druffel T., Wang H. (2020): Halide doping effect on solvent-synthesized lithium argyrodites Li6PS5X $(\mathrm{X}=\mathrm{Cl}, \mathrm{Br}, \mathrm{I})$ superionic conductors. Journal of Power Sources, 464, 228158. doi: 10.1016/j.jpowsour.2020.228158

11. Tsukasaki H., Mori S., Shiotani S., Yamamura H., Iba H. (2017): Direct observation of a non-isothermal crystallization process in precursor $\mathrm{Li}_{10} \mathrm{GeP}_{2} \mathrm{~S}_{12}$ glass electrolyte. Journal of Power Sources, 369, 57-64. doi: 10.1016/j. jpowsour.2017.09.070

12. Blanchard D., Nale A., Sveinbjörnsson D., Eggenhuisen T.M., Verkuijlen M.H.W., Suwarno Vegge T., Kentgens A.P.M., de Jongh, P.E. (2015): Nanoconfined $\mathrm{LiBH}_{4}$ as a fast lithium ion conductor. Advanced Functional Materials, 25, 184-192. doi: 10.1002/adfm.201402538

13. Knauth P. (2009): Inorganic solid Li ion conductors: An overview, Solid State Ionics, 180, 911-916. doi: 10.1016/j. ssi.2009.03.022

14. Inaguma Y., Nakashim M. (2013): A rechargeable lithium air battery using a lithium ion-conducting lanthanum lithium titanate ceramics as an electrolyte separator, Journal Power Sources, 228, 250-255. doi: 10.1016/j.jpowsour.2012.11. 098

15. Geng H., Lan J., Mei A., Lin Y., Nan C.W. (2011): Effect of sintering temperature on microstructure and transport properties of $\mathrm{Li}_{3 x} \mathrm{La}_{2 / 3-x} \mathrm{TiO}_{3}$ with different lithium contents. Electrochimica Acta, 56, 3406-3414. doi: 10.1016/j. electacta.2010.06.031

16. Teranishi T., Yamamoto M., Hayashi H., Kishimoto A (2013): Lithium ion conductivity of Nd-doped ( $\mathrm{Li}, \mathrm{La}) \mathrm{TiO}_{3}$ ceramic, Solid State Ionics, 243, 18-21. doi: 10.1016/j.ssi. 2013.04.014

17. Abhilash K.P., Selvin P.C., Nalini B., Nithyadharseni P., Pillai B.C. (2013): Investigations on pure and Ag doped lithium lanthanum titanate (LLTO) nanocrystalline ceramic electrolytes for rechargeable lithium-ion batteries. Ceramics International, 39, 947-952. doi: 10.1016/j.ceramint. 2012.07.011
18. Le H.T.T., Kalubarme R.S., Ngo D.T., Jang S., Jung K., Shin K., Park C.J. (2015): Citrate gel synthesis of aluminumdoped lithium lanthanum titanate solid electrolyte for application in organic-type lithium-oxygen batteries. Journal of Power Sources, 274, 1188-1199. doi: 10.1016/j.jpowsour. 2014.10.146

19. Deng Y., Shang S., Mei A., Lin Y., Liu L., Nan C. (2009): The preparation and conductivity properties of $\mathrm{Li}_{0.5} \mathrm{La}_{0.5} \mathrm{TiO}_{3}$ inactive second phase composites. Journal the Alloys and Compounds, 472, 456-460. doi: 10.1016/j. jallcom.2008.04.085

20. Zhang H., Liu X., Qi Y., Liu V. (2013): On the $\mathrm{La}_{2 / 3-x} \mathrm{Li}_{3 x} \mathrm{TiO}_{3} /$ $\mathrm{Al}_{2} \mathrm{O}_{3}$ composite solid-electrolyte for Li-ion Conduction. Journal the Alloys and Compounds, 577, 57-63. doi: 10.1016/j.jallcom.2013.04.195

21. Lineva B.A., Kobylyanskaya S.D., Kovalenko L.L., V'yunov O.I., Belous A.G. (2017): Effect of impurities on the electrical properties of the defect perovskite $\mathrm{Li}_{0.33} \mathrm{La}_{0.57} \mathrm{TiO}_{3}$. Inorganic Materials, 53, 326-332. doi: 10.1134/ S0020168517030074

22. Chen K., Huang M., Shen Y., Lin Y., Nan C.W. (2012): Enhancing ionic conductivity of $\mathrm{Li}_{0.35} \mathrm{La}_{0.55} \mathrm{TiO}_{3}$ ceramics by introducing $\mathrm{Li}_{7} \mathrm{La}_{3} \mathrm{Zr}_{2} \mathrm{O}_{12}$. Electrochimica Acta, 80 , 133-139. doi: 10.1016/j.electacta.2012.06.115

23. Onishi H., Takai S., Yabutsuka T, Yao T. (2016): Synthesis and Electrochemical Properties of LATP-LLTO Lithium Ion Conductive Composites. Electrochemistry, 84, 967-970. doi: 10.5796/electrochemistry.84.967

24. Abhilash K.P., Christopher Selvin P., Nalini B., Somasundaram K., Sivaraj P., Chandra Bose A. (2016): Study of the temperature dependent transport properties in nanocrystalline lithium lanthanum titanate for lithium ion batteries. Journal of Physical and Chemistry of Solids, 91, 114-121. doi: 10.1016/j.jpcs.2015.12.015

25. Zachary D.G., Yang T., Morgado G.B.G., Chan C.K. (2016): Preparation of nano- and microstructured garnet $\mathrm{Li}_{7} \mathrm{La}_{3} \mathrm{Zr}_{2} \mathrm{O}_{12}$ solid electrolytes for Li-Ion batteries via cellulose templating. ACS Sustainable Chemistry \& Engineering, 4, 6391-6398. doi: 10.1021/acssuschemeng. $6 \mathrm{~b} 01032$ 